\title{
Genital and Urinary Tract Obstruction as a Late Complication of Female Genital Mutilation at Latifa Hospital, Dubai, UAE-Case Report
}

\author{
Laila Yahya A. Alhubaishi' ${ }^{1}$, Faiza Badawi ${ }^{1}$, Hassan Y. Hotait ${ }^{2}$, G. Lakshmiah ${ }^{2}$, Atif Bashir Fazari ${ }^{1,3^{*}}$ \\ ${ }^{1}$ Department of Obstetrics \& Gynecology, Latifa Hospital, DHA, Dubai, UAE \\ ${ }^{2}$ Department of Histopathology \& Genetics, Dubai Hospital, DHA, Dubai, UAE \\ ${ }^{3}$ Faculty of Medicine, University of Medical Sciences \& Technology, Khartoum, Sudan \\ Email: *atiffazari@hotmail.co.uk
}

How to cite this paper: Alhubaishi, L.Y.A. Badawi, F., Hotait, H.Y., Lakshmiah, G. and Fazari, A.B. (2019) Genital and Urinary Tract Obstruction as a Late Complication of Female Genital Mutilation at Latifa Hospital, Dubai, UAE-Case Report. Open Journal of Obstetrics and Gynecology, 9, 223-228.

https://doi.org/10.4236/ojog.2019.92023

Received: January 23, 2019

Accepted: February 16, 2019

Published: February 19, 2019

Copyright $\odot 2019$ by author(s) and Scientific Research Publishing Inc. This work is licensed under the Creative Commons Attribution International License (CC BY 4.0).

http://creativecommons.org/licenses/by/4.0/

\section{(c) (i) Open Access}

\begin{abstract}
Female genital mutilation (FGM) is partial or total excision of female external genitalia or other deliberate injury to the female genital organs for non-therapeutic purpose. It is cultural and traditional practice. Female genital mutilation may result in immediate complications such as severe pain and bleeding and long-term complications such as: psychological, psychosexual, trauma, infertility, urinary and genital complications.
\end{abstract}

\section{Keywords}

Female Genital Mutilation, Infibulation, Urine Retention, Defibulation

\section{Introduction}

Female genital mutilation (FGM), also known as "female genital cutting", "female genital mutilation/cutting" or "cutting" (FGM/C), refers to "all procedures involving partial" or total removal of the external female genitalia or other injury to the female genital organs for non-medical reasons [1]. This practice is rarely among aboriginals Gulf region.

FGM involves partial or total removal of the external female genitalia or other injury to the female genital organs for nonmedical reasons [2].

FGM is an ancient tradition that crosses national frontiers but is primarily practiced in 28 countries in Central and East Africa with the highest prevalence found in Egypt, Ethiopia, Guinea, Mali, Somalia, and Sudan [3]. It has been estimated that 130 - 140 million girls and women are affected by FGM and that every year about 3 million more female children are at risk of undergoing the 
procedure. While most widespread in Africa, the practice also occurs among immigrant communities in North America and Europe [4].

More than 200 million girls and women have undergone FGM, with three million at risk each year [3].

Female genital mutilation may result in immediate complications such as severe pain and bleeding and long-term complications such as: psychological, psychosexual, trauma, infertility, susceptibility to bacterial vaginosis, and genital herpes and obstetric complications including perinatal death. All types of FGM have been shown to be associated with complications. [5].

Nearly all medical professional organizations, led by WHO and the World Medical Association, have condemned FGM and consider it a violation of human rights [6].

We present a 56 years postmenopausal woman referred with recurrent urine retention with urinary and genital tract obstruction following long-last female genital mutilation. She was managed by elective defibulation, with a satisfactory outcome.

\section{Case Report}

56 years P4 Postmenopausal lady and no post-menopausal bleeding no sexual activity. Presented to medical department with difficulty in passing urine with occasional dysuria 3 years increased since one month. Referred for difficult catheterization. She is known case of Behcet's disease, diabetes, hypertension, hyperlipdemia and osteoarthiritis. All her medical co-morbidities are well control and on regular well tolerated medications.

On examination she is stable not in pain. Normal blood pressure reading and no oral ulcer. Abdomen is soft, lax with midline infra-umbilical scar for Caesarean section and mass.

Local external genitalia examination revealed badly scared genitalia with complete excision of external genitalia and stitching of the two cut sides together at midline in clear dry tough scar. There is small tinny orifice down at the end of the scarred area near the anus, it seems the urine pass through (Figure 1). This represents typical Type III FGM according to the World health organization (WHO) classification of FGM (Table 1).

The patient's was carefully checked by anaesthetist, internalist and prepared for surgery after detailed counselling and explanation following the hospital policy in surgical procedures.

The patient was well investigated in detail for blood sugar profiles, complete blood count, lipid profiles, renal functions tests, liver function tests all within the normal ranges. The, urine chemistry is normal, urine culture and sensitivity was negative for microbiological growth. Because the surgery was considered a moderate-level surgical procedure, the patient was seen by an anaesthetist and the operation performed under low spinal anaesthesia. Under optimal aseptic conditions and the patient in lithotomy position, the following steps were performed. 
Table 1. WHO classification of female genital mutilation.

\begin{tabular}{cl}
\hline Type & \\
\hline Type I & Partial or total removal of clitoris and/or prepuce \\
Type II & Partial of total removal of clitoris and labia minora, with or without excision of labia majora \\
Type III & Infibulation. Excision of part or all of external genitalia and stitching of the two cut sides together to varying degrees \\
Type IV & $\begin{array}{l}\text { All other harmful procedures to female genitalia for non-medical purposes, for example pricking, piercing, incision, } \\
\text { stretching, scraping and cauterisation }\end{array}$ \\
\hline
\end{tabular}

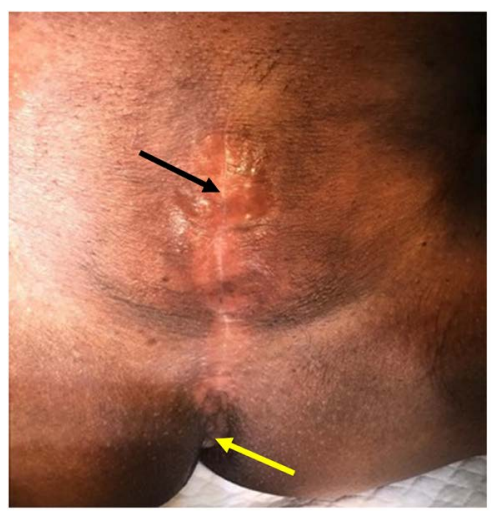

Figure 1. Clinical photograph of complete excised external genitalia with midline scar (black arrow). The small open site (yellow arrow).

She had an elective defibulation, which consisted of splitting the fused remains of the vulva with part of labia minora was seen in the midline superiorly, till the anatomical site of the clitoris was exposed and freed from the tethering fibrous tissue. The cut edges of the tough fibrous tissues were sutured together with running sutures of 3/0 Vicryl 3/0, Figure 2, and separated by means of gauze dressings, during the healing period, to prevent cross adhesions. Some of the tissues at the margins carefully excised in millimetres and sent for histopathology. Based on in mind her menopausal status, Bechet disease history and the dryness of the vulva tissue histopathology study will exclude other possible pathology.

The vagina and the cervix were well inspected both are normal with no pathology. She was discharged home on the same postoperative day with clear perineal hygienic advice and to be reviewed in the Outpatient Clinic on the one, two, four, six postoperative weeks later. Her wounds were well-healed and she was voiding freely and she was happy and well satisfied with no more urinary symptom. The histopathology result proves vulval skin sections reveal multiple pieces of skin with basket woven orthokeratosis and mild epidermal hyperplasia. Basal layer shows melanin pigmentation and focal pigment loss. The upper dermis shows moderate inflammatory cell infiltrate mainly composed of lymphocytes, histiocytes and scattered melanophages. No evidence of interface dermatitis or basal vacuolar degeneration is identified, it is only post inflammatory hyperpigmentation. Figure 3 excluding others pathology. This result was discussed with patient, well convinced. 


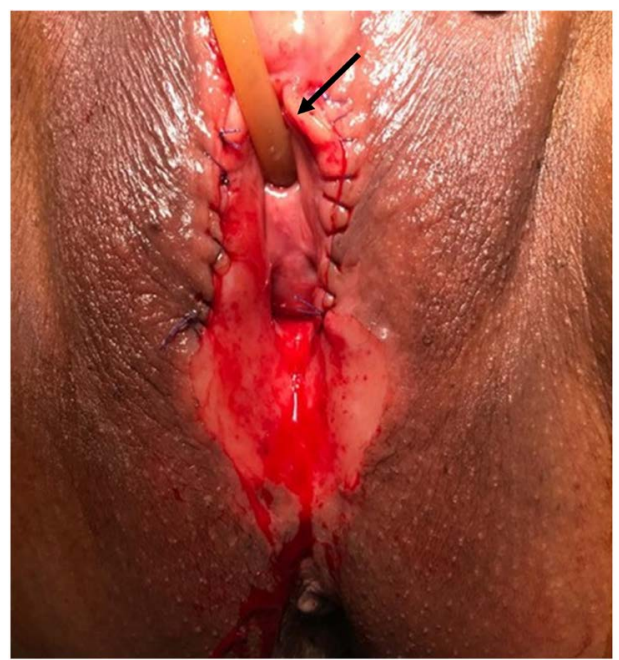

Figure 2. Clinical photograph of defibulation wound with part of labia minora seen (black arrow).

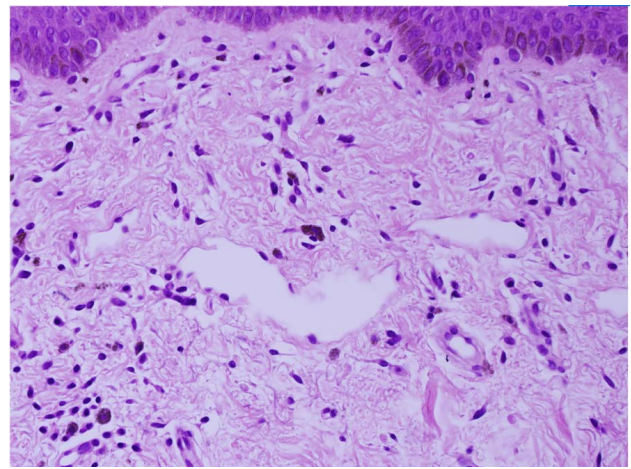

Figure 3. Histopathology slide photograph shows high power view of dermis with inflammatory cell infiltrate and pigment containing macrophages.

\section{Discussion}

Female genital mutilation is a dangerous practice that is fraught with several complications. FGM is usually underreported women health issue and this makes FG Meradication difficult.

Many FGM complications are reported and varied in how much affecting women health at their different ages of their life. The FGM complications listed as immediate, early and late complications (Table 2).

In systematic review by Berg, the most common immediate complications from FGM were haemorrhage (5\% - 62\%), urinary retention ( $8 \%-53 \%)$ and genital swelling $(2 \%-27 \%)$, although there were additional studies reporting infection and fever, and three deaths directly. This systematic review also demonstrated an association of FGM with urinary tract infection, dyspareunia and bacterial vaginosis [7].

FGM has a very bad psychological and/or organic and physical damage. Urological complications have also been reported to occur following FGM and lasts for long time and mandates some intervention. 
Table 2. Complications of FGM.

\begin{tabular}{ll}
\hline \multicolumn{1}{c}{ Immediate and early complications } & \multicolumn{1}{c}{ Late complications } \\
\hline Severe pain & Urinary problems (painful urination, urinary tract infections \\
Haemorrhage & Vaginal hygienic problems \\
Infections and sepsis & Scar tissue and keloid formation \\
Urinary problems urine retension & Sexual problems and penetration difficulties) \\
Injury to surrounding genital tissue & Increased risk of childbirth complications \\
Shock (haemorrhagic and septic shock) & Need for later surgeries: (defibulation). repeated opening and closing procedures (Redo procedure) \\
Death & Psychological problems (depression, anxiety, post-traumatic stress disorder, low self-esteem) \\
\hline
\end{tabular}

Defibulation as surgical procedure as it was done performed here is the option of management of FGM type III. Defibulation involves incising the fused labia minora to restore the introital opening [8]. Usually can be performed under general or regional anaesthesia.

The way of suturing in interrupted or running manner has no difference in terms of healing. The running suture is preferred as the interrupted one associated with postoperative discomfort and irritation.

Counselling of these cases for such intervention as defibulation or reconstructive surgery if needed is mandatory in case management and satisfaction by the new anatomical shape which may not restored because of the FGM damage but at least makes some of the area function with less if no urogenital compliant.

Post-operative wound care and hygiene play important rule in healing.

\section{Conclusion}

Female genital mutilation is a dangerous and dehumanizing traditional practice that needs to be stopped. It has long term complications that might affect quality of life. Many efforts were done to stop FGM with touchable progress but every now and then FGM complication is still seen. However, more legislation is not enough to stop the practice.

\section{Acknowledgements}

Special thanks to Latifa hospital administration and staff with appreciation for this case care.

\section{Ethical Approval}

Informed consent obtained from the case herself with agreement of Obstetrics\& Gynecology department for publication.

\section{Conflicts of Interest}

Nothing to disclose and conflict of interest.

\section{References}

[1] United Nations Children's Fund (2013) Female Genital Mutilation/Cutting: A Sta- 
tistical Overview and Exploration of the Dynamics of Change. UNICEF, New York.

[2] World Health Organization (2008) Eliminating Female Genital Mutilation: An Interagency Statement-OHCHR, UNAIDS, UNDP, UNECA, UNESCO, UNFPA, UNHCR, UNICEF, UNIFEM, WHO.

http://www.who.int/reproductivehealth/publications/fgm/9789241596442/en/

[3] United Nations Children's Fund (2016) Female Genital Mutilation/Cutting: A Global Concern. UNICEF, New York.

http://www.unicef.org/media/files/FGMC_2016_brochure_final_UNICEF_SPREAD .pdf

[4] Fazari, A.B., Berg, R.C., Mohammed, W.A., Gailii, E.B. and Elmusharaf, K. (2013) Reconstructive Surgery for Female Genital Mutilation Starts Sexual Functioning in Sudanese Woman: A Case Report. Journal of Sexual Medicine, 10, 2861-2865. https://doi.org/10.1111/jsm.12286

[5] Obi, A. and Onoh, R. (2012) Urinary and Genital Tract Obstruction as a Complication of Female Genital Mutilation. Journal of Surgical Technique and Case Report, 4, 64-66. https://doi.org/10.4103/2006-8808.100360

[6] WHO (2008) Eliminating Female Genital Mutilation: An Interagency Statement. WHO, Geneva.

[7] Berg, R.C., Underland, V., Odgaard-Jensen, J., Fretheim, A. and Vist, G.E. (2014) Effects of Female Genital Cutting on Physical Health Outcomes: A Systematic Review and Meta-Analysis. BMJ Open, 4, e006316. https://doi.org/10.1136/bmjopen-2014-006316

[8] Collinet, P., Sabban, F., Lucot, J.P., Boukerrou, M., Stien, L. and Lerroy, J.L. (2004) Management of Type III Female Genital Mutilation. Journal de Gynécologie Obstétrique et Biologie de la Reproduction (Paris), 33, 720-724. https://doi.org/10.1016/S0368-2315(04)96633-1 